Article

\title{
Synthesis, Structure, and Properties of Coordination Polymers Based on 1,4-Bis((2-methyl-1H-imidazol-1- yl)methyl)benzene and Different Carboxylate Ligands
}

\author{
Kang Liu (D), Yaowen Zhang, Liming Deng, Shaoshao Jiao, Zhenyu Xiao, Fan Cao and Lei Wang * \\ Key Laboratory of Eco-chemical Engineering, Ministry of Education, Laboratory of Inorganic Synthesis and \\ Applied Chemistry, College of Chemistry and Molecular Engineering, Qingdao University of Science and \\ Technology, Qingdao 266042, China; liukang82@126.com (K.L.); sw_zhangyw@163.com (Y.Z.); \\ ccedenglm@163.com (L.D.); jiaoss0309@163.com (S.J.); inorgxiaozhenyu@163.com (Z.X.); \\ caofan_success@126.com (F.C.) \\ * Correspondence: inorchemw1@126.com; Tel.: +86-532-840-22681
}

Received: 31 May 2018; Accepted: 11 July 2018; Published: 13 July 2018

\begin{abstract}
Three novel coordination polymers, formulated as $\left\{\left[\mathrm{Zn}(1,4-\mathrm{bmimb})(\mathrm{PhAA})_{2}\right] \cdot \mathrm{H}_{2} \mathrm{O}\right\}_{\mathrm{n}}(\mathbf{1})$, $\left[\mathrm{Cu}(1,4-\mathrm{bmimb})_{0.5}(2,6-\mathrm{PyDC})\right]_{\mathrm{n}}(2)$, and $\left\{\left[\mathrm{Cu}(1,4-\mathrm{bmimb})_{0.5}(2-\mathrm{PAC})(\mathrm{HCOO})\right] \cdot 2 \mathrm{H}_{2} \mathrm{O}\right\}_{\mathrm{n}}(3)(1,4-\mathrm{bmimb}$ = 1,4-bis $((2$-methyl-1H-imidazol-1-yl $)$ methyl $)$ benzene; PhAA = phenylacetic acid; 2,6-PyDC = pyridine-2,6-dicarboxylic acid; 2-PAC $=2$-pyrazinecarboxylic acid), were synthesized by the self-assembly of mixed ligands with $\mathrm{Zn}$ (II) and $\mathrm{Cu}(\mathrm{II})$ under solvothermal conditions and characterized by means of single-crystal X-ray diffraction, X-ray powder diffraction, infrared spectra, thermogravimetric analysis, fluorescence spectra and UV-vis absorption spectra. $\mathbf{1}$ is shown as a Z-shaped chain, which is formed by $\mathrm{Zn}^{2+}$, PhAA ligands, and 1,4-bmimb ligands, and is assembled into a 3D structure by hydrogen bonding and $\pi \cdots \pi$ interaction. Similarly, 2 displays a single chain, which is built by $\mathrm{Cu}^{2+}, 2,6-\mathrm{PyDC}$ ligands, and 1,4-bmimb ligands, and is assembled into a 3D structure by hydrogen bonding and $\pi \cdots \pi$ interaction. 3 possesses a $1 D$ ladder structure, which is formed by $\mathrm{Cu}^{2+}, 2,6-\mathrm{PyDC}$ ligands, and 1,4-bmimb ligands, and is assembled into a 3D structure by hydrogen bonding. The luminescence properties (for $\mathbf{1}$ ) and UV-vis spectrum (for $\mathbf{2}$ and $\mathbf{3}$ ) were also studied and discussed.
\end{abstract}

Keywords: solvothermal synthesis; coordination polymers; mixed-ligand; photoluminesce properties

\section{Introduction}

Coordination polymers (CPs), a series of solid-state materials with an infinite framework structure, are generated by the self-assembly of metal ions and organic ligands [1-4]. CPs are continuously gaining attention owing to their appealing structures and various potential applications in luminescence, catalysis, magnetism, drug delivery, gas adsorption and separation, and so on [5-11]. It is apparent that certain structures give materials unique properties, which are crucial for the application of the material [12-14]. However, the design and manufacture of novel functional CPs remain a serious challenge at present.

There are many factors (metal ions, ligands, solvents, $\mathrm{pH}$, etc.) that can affect the synthesis of CPs. The most effective strategy for the synthesis of valuable CPs is selecting suitable organic ligands [15-19]. Crystal engineers select diverse ligands to purposefully synthesize CPs [20,21]. Although it is a convenient strategy to construct a $\mathrm{CP}$ using a single ligand, to obtain unique structures, crystal engineers are more likely to use mixed ligands to manufacture CPs [22-25].

Among the reported studies, a mixture of 1,4-bmimb ligand and carboxylic acid ligands has been applied extensively in the construction of novel CPs due to the excellent coordination 
modes of these ligands [26-28]. N-donor organic ligands (such as bis-imidazolium) have been extensively studied to construct stable CPs containing nitrogen-metal bonds. The mixture of carboxylic acid and nitrogen-containing ligands not only helps to enrich structures but also supports the addition of their own characteristics to new CPs. In the present paper, we report herein the solvothermal synthesis, crystal structures, thermal stability, luminescent properties, and UV-vis spectra of three novel coordination compounds, which are named $\left\{\left[\mathrm{Zn}(1,4-\mathrm{bmimb})(\mathrm{PhAA})_{2}\right] \cdot \mathrm{H}_{2} \mathrm{O}\right\}_{\mathrm{n}}$ (1), $\left[\mathrm{Cu}(1,4-\mathrm{bmimb})_{0.5}(2,6-\mathrm{PyDC})\right]_{\mathrm{n}}(2)$, and $\left\{\left[\mathrm{Cu}(1,4-\mathrm{bmimb})_{0.5}(2-\mathrm{PAC})(\mathrm{HCOO})\right] \cdot 2 \mathrm{H}_{2} \mathrm{O}\right\}_{\mathrm{n}}(3)$.

\section{Materials and Methods}

\subsection{Materials and Physical Measurements}

The reagents and drugs used in the experiment were obtained directly from commercial sources and used without further purification. Infrared (IR) spectra were recorded on a NEXUS 670 FTIR spectrometer (Thermo Nicolet Corporation, Madison, WI, USA) with KBr pellets in the range of $400-4000 \mathrm{~cm}^{-1}$. Elemental analyses $(\mathrm{C}, \mathrm{H}$, and $\mathrm{N})$ were performed using an EA 1110 elemental analyzer (Carlo-Erba Corporation, Sandwich, Italy). Powder X-ray diffraction (PXRD) measurements were executed using a Rigaku D/Max-2500 diffractometer (Rigaku Corporation, Tokyo, Japan) at $40 \mathrm{kV}$ and $40 \mathrm{~mA}$ with a Cu-target tube and a graphite monochromator. The recording speed was $6^{\circ} \mathrm{min}^{-1}$ at room temperature. Thermogravimetric analysis (TGA) was performed using an SDT Q600 instrument (TA Instruments, New Castle, DE, USA) with a heating rate of $10{ }^{\circ} \mathrm{C} \mathrm{min}-1$ in a flowing $\mathrm{N}_{2}$ atmosphere. The solid fluorescence test was performed using an Edinburgh Hitachi F-4500 fluorescence spectrophotometer (Hitachi Limited, Tokyo, Japan) with a power of $450 \mathrm{~W}$ at room temperature. During the test, the crystal powder was flatly adhered to a clean glass plate. The amount of sample used for each test was $20 \mathrm{mg}$.

\subsection{Methods}

\subsubsection{Synthesis of $\left\{\left[\mathrm{Zn}(1,4-\mathrm{bmimb})(\mathrm{PhAA})_{2}\right] \cdot \mathrm{H}_{2} \mathrm{O}\right\}_{\mathrm{n}}(\mathbf{1})$}

$\mathrm{Zn}\left(\mathrm{NO}_{3}\right)_{2} \cdot 6 \mathrm{H}_{2} \mathrm{O}(0.2974 \mathrm{~g}, 1 \mathrm{mmol}), \mathrm{PhAA}(0.0681 \mathrm{~g}, 0.5 \mathrm{mmol})$, and 1,4-bmimb (0.1282 $\mathrm{g}$, $0.5 \mathrm{mmol})$ were dissolved in a mixture of DMF $(2.5 \mathrm{~mL})$ and deionized water $(2.5 \mathrm{~mL})$. The solution was then transferred to a $10 \mathrm{~mL}$ glass bottle. The sealed bottle was heated under autogenous pressure at $100{ }^{\circ} \mathrm{C}$ for 2 days and cooled in air to room temperature. After being collected by filtration, colorless crystals were washed several times with $\mathrm{DMF} / \mathrm{H}_{2} \mathrm{O}\left(\mathrm{V}_{\mathrm{DMF}} / \mathrm{V}_{\text {water }}=1 / 1\right)$, and dried at $45^{\circ} \mathrm{C}$. Yield: $62 \%$. Anal. calcd for $\mathrm{C}_{32} \mathrm{H}_{34} \mathrm{~N}_{4} \mathrm{O}_{5} \mathrm{Zn}(\%)$ : C 61.99, H 5.53, N 9.03. Found: C 61.78, H 5.64, N 8.96. IR (KBr disc, cm $\left.{ }^{-1}\right)$ : $3453(\mathrm{~m}), 3142(\mathrm{~s}), 3026(\mathrm{~s}), 2931$ (s), $1640(\mathrm{w}), 1627(\mathrm{w}), 1516(\mathrm{~m}), 1433(\mathrm{w}), 1339(\mathrm{~m})$, $1281(\mathrm{~m}), 1167(\mathrm{w}), 1073(\mathrm{~m}), 1020(\mathrm{~s}), 943(\mathrm{~m}), 886(\mathrm{~s}), 833(\mathrm{~m}), 685(\mathrm{~m}), 661(\mathrm{~m}), 605(\mathrm{~m})$.

\subsubsection{Synthesis of $\left[\mathrm{Cu}(1,4-\mathrm{bmimb})_{0.5}(2,6-\mathrm{PyDC})\right]_{\mathrm{n}}(\mathbf{2})$}

A mixture of $\mathrm{Cu}\left(\mathrm{NO}_{3}\right)_{2} \cdot 6 \mathrm{H}_{2} \mathrm{O}(0.2956 \mathrm{~g}, 1 \mathrm{mmol}), 2,6-\mathrm{PyDC}(0.0835 \mathrm{~g}, 0.5 \mathrm{mmol})$, and 1,4-bmimb $(0.1282 \mathrm{~g}, 0.5 \mathrm{mmol})$ in ethanol $/$ water $\left(\mathrm{V}_{\text {ethanol }} / \mathrm{V}_{\text {water }}=1 / 1,5 \mathrm{~mL}\right)$ was placed in a $10 \mathrm{~mL}$ glass bottle. The sealed vessel was heated at $90{ }^{\circ} \mathrm{C}$ for 3 days and then cooled to room temperature, giving the blue block crystals of 2 . In the same procedure as that described for $\mathbf{1}$, crystals were dried in air after filtration and washed with ethanol $/ \mathrm{H}_{2} \mathrm{O}\left(\mathrm{V}_{\text {ethanol }} / \mathrm{V}_{\text {water }}=1 / 1\right)$. Yield: $67 \%$. Anal. calcd for $\mathrm{C}_{15} \mathrm{H}_{12} \mathrm{CuN}_{3} \mathrm{O}_{4}$ (\%): C 49.79, H 3.34, N 11.61. Found: C 49.82, H 3.38, N 11.67. IR (KBr disc, $\left.\mathrm{cm}^{-1}\right)$ : $3433(\mathrm{~s}), 3138(\mathrm{~m}), 3065(\mathrm{~s}), 2926(\mathrm{w}), 1627(\mathrm{~s}), 1541(\mathrm{w}), 1508(\mathrm{w}), 1458(\mathrm{~m}), 1375(\mathrm{~m}), 1285(\mathrm{w}), 1149(\mathrm{w})$, $987(\mathrm{~m}), 828(\mathrm{~s}), 735(\mathrm{~m}), 678(\mathrm{w})$.

\subsubsection{Synthesis of $\left\{\left[\mathrm{Cu}(1,4-\mathrm{bmimb})_{0.5}(2-\mathrm{PAC})(\mathrm{HCOO})\right] \cdot 2 \mathrm{H}_{2} \mathrm{O}\right\}_{n}(3)$}

Compound 3 was synthesized using a procedure similar to 1 except that PhAA was replaced by 2-PAC $(0.0620 \mathrm{~g}, 0.5 \mathrm{mmol})$. Blue block crystals suitable for single-crystal X-ray diffraction analysis 
were collected by filtration, washed several times with a mixed solvent $\left(\mathrm{V}_{\mathrm{DMF}} / \mathrm{V}_{\text {water }}=1 / 1\right)$, and then dried in air. Yield: $67 \%$. Anal. calcd for $\mathrm{C}_{14} \mathrm{H}_{17} \mathrm{CuN}_{4} \mathrm{O}_{6}$ (\%): C 41.95, H 4.27, N 13.98. Found: C 41.85, H 4.22, N 13.94. IR (KBr disc, $\mathrm{cm}^{-1}$ ): 3463 (s), 3142 (m), 3034 (s), 2933 (w), 1657 (s), 1521 (w), 1503 (w), $1458(\mathrm{~m}), 1375(\mathrm{~m}), 1283(\mathrm{w}), 1141(\mathrm{w}), 933(\mathrm{~m}), 856(\mathrm{~s}), 738(\mathrm{~m}), 673(\mathrm{w})$.

\subsubsection{IR Spectra}

The IR spectra of the obtained coordination polymers is in accordance with their single crystal structures. For instance, compounds show strong and broad absorption bands in the range 3400-3500 $\mathrm{cm}^{-1}$, demonstrating the presence of the $\mathrm{O}-\mathrm{H}$ stretching modes within the coordinated or lattice water molecules. The absence of any obvious absorption band in the region of $1700 \mathrm{~cm}^{-1}$ signifies full deprotonation of the original carboxylic ligands. The $\mathrm{C}-\mathrm{H}$ vibration band for benzene exhibited characteristic absorptions in the range of $3000-3300 \mathrm{~cm}^{-1}$, and the methyl C-H stretching vibration band on the 1,4-bmimb ligand was detected at $2900-3000 \mathrm{~cm}^{-1}$. The $\mathrm{C}=\mathrm{N}$ and $\mathrm{C}=\mathrm{C}$ stretching vibration band of the ligands appeared in the range of $1500-1650 \mathrm{~cm}^{-1}$.

\subsection{Crystal Structure Determination}

Three appropriately sized crystals $(0.27 \mathrm{~mm} \times 0.26 \mathrm{~mm} \times 0.24 \mathrm{~mm}(\mathbf{1}), 0.28 \mathrm{~mm} \times 0.26 \mathrm{~mm} \times$ $0.24 \mathrm{~mm}(2)$, and $0.27 \mathrm{~mm} \times 0.24 \mathrm{~mm} \times 0.22 \mathrm{~mm}(3))$, were picked under a microscope and measured on a single crystal diffractometer named Siemens SMART (Siemens Limited, Berlin, Germany). This instrument

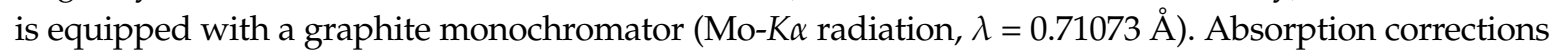
were executed using the SADABS program (Version 2.03) [29]. The structure was solved by direct methods using SHELXS-97 [30] and refined by full-matrix least-squares techniques using SHELXL-2014/7 (Sheldrick, 2014) [31]. Hydrogen atoms were placed in calculated positions and included as riding atoms with isotropic displacement parameters 1.2-1.5 times the $U_{\text {eq }}$ of the attached atoms. The O-H hydrogen atoms of water were placed in calculated positions and refined using a SHELX DFIX restraint to fix their positions in the structure of 1 , and using SHELX DFIX and DANG restraints in 3 . The $\mathrm{C}-\mathrm{H}$ hydrogen atoms on methyl were held in calculated positions by HFIX 137 in the structures of 1-3. Related information belonging to the crystallographic parameters and structure refinement is revealed in Table 1 . Selected bond lengths and angles are listed in Tables S1-S3. Hydrogen bond parameters are listed in Tables S4-S6.

CCDC (1843844 for 1, 1843845 for 2, 1843846 for 3) contains the supplementary crystallographic information for this paper.

Table 1. Crystal data and structure refinement details of compounds 1-3.

\begin{tabular}{cccc}
\hline Compound & $\mathbf{1}$ & $\mathbf{2}$ & $\mathbf{3}$ \\
\hline Empirical formula & $\mathrm{C}_{32} \mathrm{H}_{34} \mathrm{~N}_{4} \mathrm{O}_{5} \mathrm{Zn}$ & $\mathrm{C}_{15} \mathrm{H}_{12} \mathrm{CuN}_{3} \mathrm{O}_{4}$ & $\mathrm{C}_{56} \mathrm{H}_{68} \mathrm{Cu}_{4} \mathrm{~N}_{16} \mathrm{O}_{24}$ \\
Formula weight & 620.02 & 361.82 & 1603.46 \\
Temperature/K & $293(2)$ & $293(2)$ & $293(2)$ \\
Crystal system & Monoclinic & Triclinic & Monoclinic \\
Space group & $\mathrm{C} 2 / \mathrm{c}$ & $P 1$ & $P 2{ }_{1} / \mathrm{c}$ \\
$a / \AA$ & $11.4038(6)$ & $7.6721(9)$ & $4.65300(10)$ \\
$b / \AA$ & $18.1018(10)$ & $8.6074(10)$ & $14.5305(4)$ \\
$c / \AA$ & $14.5195(11)$ & $10.8246(13)$ & $25.9934(7)$ \\
$\alpha / \mathrm{deg}$ & 90 & $87.660(2)$ & 90.00 \\
$\beta / \mathrm{deg}$ & $105.0440(10)$ & $78.863(2)$ & $98.735(2)$ \\
$\gamma / \mathrm{deg}$ & 90 & $83.878(2)$ & 90.00 \\
$V / \AA \AA^{3}$ & $2894.5(3)$ & $697.21(14)$ & $1737.04(8)$ \\
$\mathrm{Z}$ & 4 & 2 & 1 \\
$D_{\mathrm{c}}\left(\mathrm{Mg} \cdot \mathrm{m}^{-3}\right)$ & 1.423 & 1.723 & 1.533 \\
$F(000)$ & 1296.0 & 368.0 & 824.0 \\
$R_{\text {int }}$ & 0.0496 & 0.0476 & 0.0183 \\
\hline
\end{tabular}


Table 1. Cont.

\begin{tabular}{cccc}
\hline Compound & $\mathbf{1}$ & $\mathbf{2}$ & $\mathbf{3}$ \\
\hline GOF & 1.049 & 1.045 & 1.044 \\
$R_{1} \mathrm{a} / w R_{2}{ }^{\mathrm{b}} I>2 \sigma(I)$ & $R_{1}=0.0292$ & $R_{1}=0.0358$ & $R_{1}=0.0412$ \\
& $w R_{2}=0.0792$ & $w R_{2}=0.0994$ & $w R_{2}=0.1162$ \\
$R_{1} / w R_{2}$ (all data) & $R_{1}=0.0310$ & $R_{1}=0.0386$ & $R_{1}=0.0422$ \\
& $w R_{2}=0.0803$ & $w R_{2}=0.1012$ & $w R_{2}=0.1171$ \\
\hline & $\mathrm{a} R_{1}=\Sigma\left(|| \mathrm{F}_{0}|-| \mathrm{F}_{\mathrm{c}} \mid \mathrm{l}\right) / \Sigma\left|\mathrm{F}_{0}\right| \mathrm{b} w R_{2}=\left[\Sigma w\left(\left|\mathrm{~F}_{0}\right|^{2}-\left|\mathrm{F}_{\mathrm{c}}\right|^{2}\right)^{2} / \Sigma\left(\mathrm{F}_{0}\right)^{2}\right]^{1 / 2}$
\end{tabular}

\section{Results and Discussion}

\subsection{Crystal Structures of $\left\{\left[\mathrm{Zn}(1,4-b m i m b)(P h A A)_{2}\right] \cdot \mathrm{H}_{2} \mathrm{O}\right\}_{n}(1)$}

The asymmetric unit of $\mathbf{1}$ consists of half aZn(II) ion, half a solvate water molecule, a phenylacetic acid ligand, and half a 1,4-bmimb ligand. As depicted in Figure 1a, Zn1 atoms are four-coordinate, adopting $\left[\mathrm{ZnN}_{2} \mathrm{O}_{2}\right]$ coordination environments. Each $\mathrm{Zn} 1$ ion is coordinated with two nitrogen atoms from two individual 1,4-bmimb ligands and two carboxylate oxygen atoms from two individual phenylacetic acid ligands. The $\mathrm{Zn}-\mathrm{N}$ bond lengths are $2.0173(15) \AA$, the $\mathrm{Zn}-\mathrm{O}$ bond lengths are $1.9498(13) \AA$, and the bond angles around the $\mathrm{Zn} 1$ centers range from $99.54(9)^{\circ}$ to $121.52(6)^{\circ}$, see Table S1.

As shown in Figure 1b, two 1,4-bmimb ligands bridge between neighboring $\mathrm{Zn}$ (II) ions in alternating layers, resulting in a Z-shaped chain structure that extends indefinitely in one dimension. These Z-shaped chains are assembled into a 2D supramolecular framework through O-H...O hydrogen-bonding interactions, detailed in Figure 1c and Table S4. Furthermore, the neighboring 2D layers are connected by $\pi \cdots \pi$ interactions (3.935 $\AA$ ) from the imidazole rings to generate a 3D supramolecular framework, shown in Figure 1d.

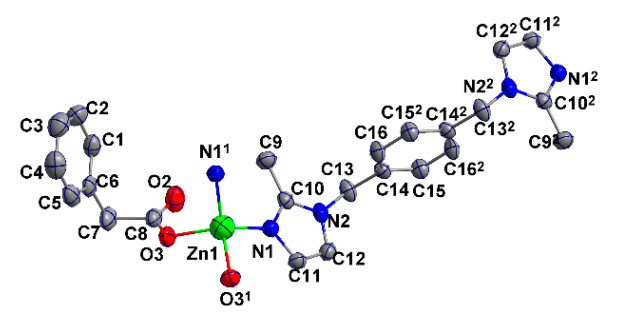

(a)

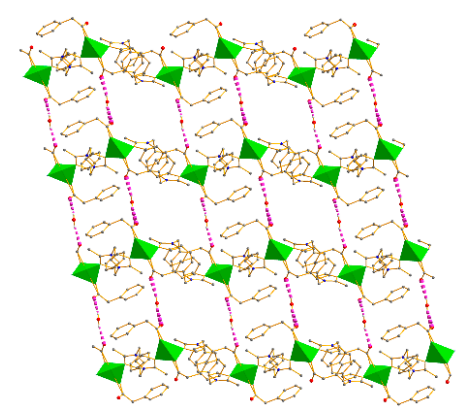

(c)

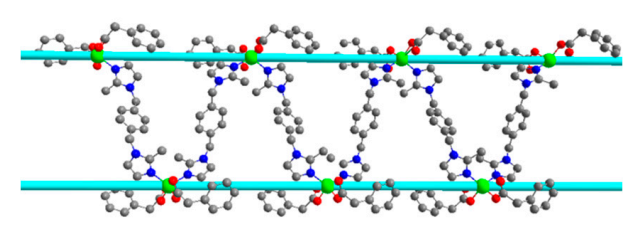

(b)

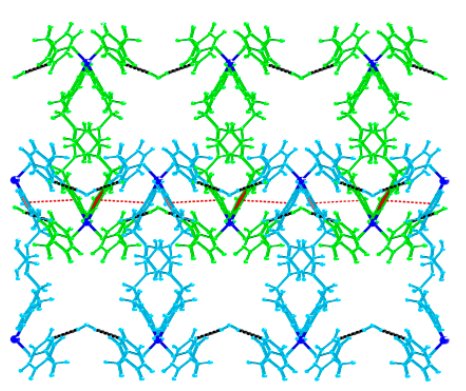

(d)

Figure 1. The structure of compound 1: (a) coordination environment of the $\mathrm{Zn}(\mathrm{II})$ ion (symmetry transformations used to generate equivalent atoms codes: ${ }^{1} 1-X,+Y, \frac{1}{2}-Z ;^{2} 1-X, 1-Y,-Z$ ); (b) 1D Z-type chain structur; (c) polyhedral representation of the 2D layer; (d) 3D framework formed by $\pi \cdots \pi$ interactions and hydrogen bonding (green, $\mathrm{Zn}$; red $\mathrm{O}$; blue, $\mathrm{N}$; gray, C). 


\subsection{Crystal Structures of $\left[C u(1,4-b m i m b)_{0.5}(2,6-P y D C)\right]_{n}(2)$}

The asymmetric unit of 2 contains a crystallographically independent $\mathrm{Cu}$ (II) ion, a 2,6-PyDC ligand, and half a 1,4-bmimb ligand. As depicted in Figure 2a, $\mathrm{Cu} 1$ atoms are five-coordinate, adopting $\left[\mathrm{CuN}_{2} \mathrm{O}_{3}\right]$ distorted hexahedron geometry coordination environments. Each $\mathrm{Cu} 1$ ion is coordinated by two nitrogen atoms and three carboxylate oxygen atoms from two individual 2,6-PyDC ligands in the equatorial plane. The $\mathrm{Cu}-\mathrm{O}$ bond lengths are, 1.9940(18) $\AA$, 2.0214(18) $\AA$ and 2.651(22) $\AA$ which are acceptable bond lengths [30,31]. The lengths of $\mathrm{Cu}-\mathrm{N}$ bonds are, 1.897(2) $\AA$ and 1.930(2) $\AA$. The angles of $\mathrm{N}-\mathrm{Cu}-\mathrm{O}$ bonds range from $80.35(9)^{\circ}$ to $102.30(8)^{\circ}$, and the angles of $\mathrm{N}-\mathrm{Cu}-\mathrm{N}$ and $\mathrm{O}-\mathrm{Cu}-\mathrm{O}$ bonds are, $176.12(8)^{\circ}$ and $160.88(8)^{\circ}$, respectively.

Figure $2 \mathrm{~b}$ shows that two 2,6-PDA ligands connect to two copper ions to form a secondary building units (SBU) and the 1,4-bmimb ligand forms a 1D Z-chain by linking adjacent SBUs. Different chains are assembled into $2 \mathrm{D}$ structures through $\mathrm{C}-\mathrm{H} \cdots \mathrm{O}$ hydrogen bonds, shown in Figure $2 \mathrm{c}$ and Table S5. In addition, the adjacent $2 \mathrm{D}$ layers are connected by $\pi \cdots \pi$ interactions (3.935 $\AA$ ) from the benzene rings to generate a 3D framework, as shown in Figure $2 \mathrm{~d}$.

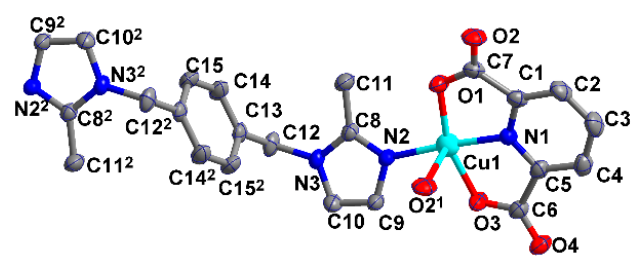

(a)

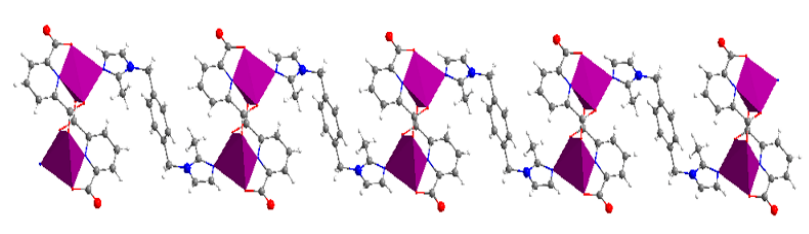

(b)

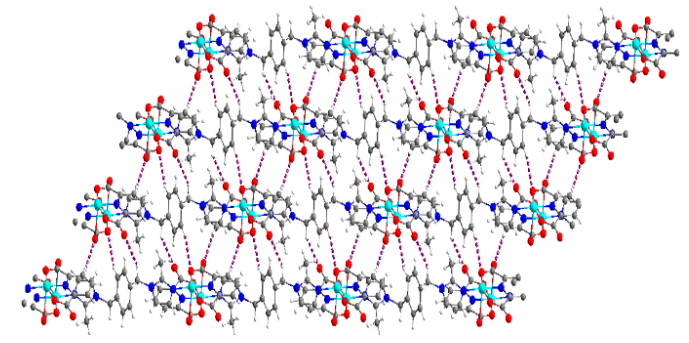

(c)

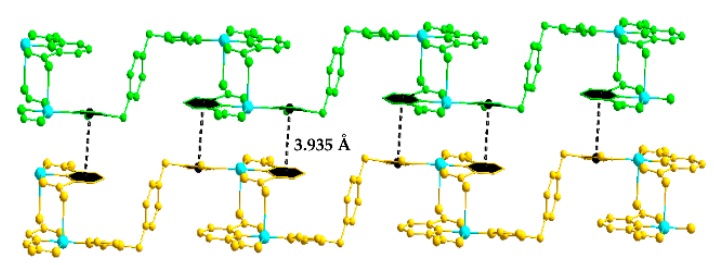

(d)

Figure 2. The structure of compound 2: (a) coordination environment of the $\mathrm{Cu}(\mathrm{II})$ ion (symmetry transformations used to generate equivalent atom codes: ${ }^{1}-\mathrm{X}, 1-\mathrm{Y}, 2-\mathrm{Z}^{2}{ }^{2}-\mathrm{X}, 1-\mathrm{Y}, 1-\mathrm{Z}$ ); (b) polyhedral representation of the 1D Z-type chain structure; (c) 2D layer formed by hydrogen bonding; (d) 3D supramolecular structure formed by $\pi \cdots \pi$ interactions (green, $\mathrm{Cu}$; red, $\mathrm{O}$; blue, N; black, C).

\subsection{Crystal Structures of $\left\{\left[\mathrm{Cu}(1,4-b m i m b)_{0.5}(2-\mathrm{PAC})(\mathrm{HCOO})\right] \cdot 2 \mathrm{H}_{2} \mathrm{O}\right\}_{n}$ (3)}

Acrystallographically independent $\mathrm{Cu}(\mathrm{II})$ ion, a 2-PAC ligand, a formate ligand, half a 1,4-bmimb ligand, and two solvate water molecules make up the asymmetric structural unit of compound 3. Figure 3 a gives a description of the coordination environment of each $\mathrm{Cu}(\mathrm{II})$ ion, highlighting the 
distorted octahedral geometry of the $\left[\mathrm{CuN}_{2} \mathrm{O}_{4}\right]$ coordination mode, which consists of two nitrogen atoms originating from a 1,4-bmimb ligand and a 2-PAC ligand and four oxygen atoms originating from three different 2-PAC ligands. The $\mathrm{Cu}-\mathrm{O}$ bond lengths are in the range of 1.9651(19) $\AA$ to 2.6320(19) $\AA$, and the lengths of $\mathrm{Cu}-\mathrm{N}$ bonds are 1.968(2) $\AA$ and 2.027(2) $\AA$. The bond angles around the $\mathrm{Cu} 1$ centers range from $54.95(7)^{\circ}$ to $174.30(8)^{\circ}$. The two oxygen atoms from the same carboxylic acid are alternately linked to copper ions, creating an infinitely-extended $-\mathrm{Cu}-\mathrm{O}-\mathrm{Cu}$ - chain, shown in Figure $3 \mathrm{~b}$. Additionally, the 1,4-bmimb ligand bridges two-Cu-O-Cu-chains to form an infinitely extended 1D ladder-shaped chain, as shown in Figure 3c. Different ladder-shaped structures build up a 3D framework that is relianton $\mathrm{O}-\mathrm{H} \cdots \mathrm{O}$ hydrogen bonds between ligands and solvate water molecules (see Figure 3d and Table S6).

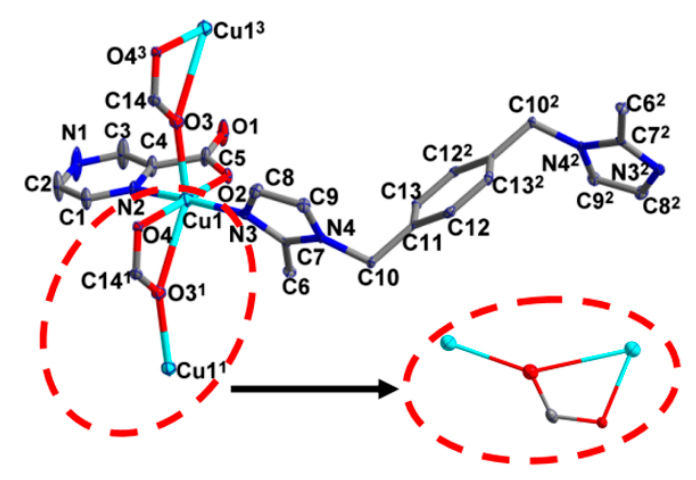

(a)

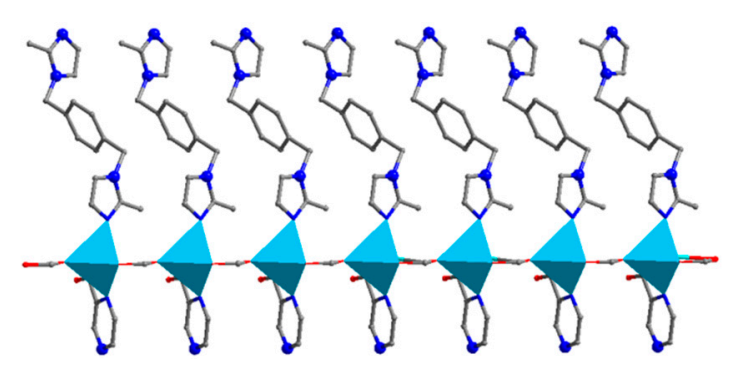

(b)

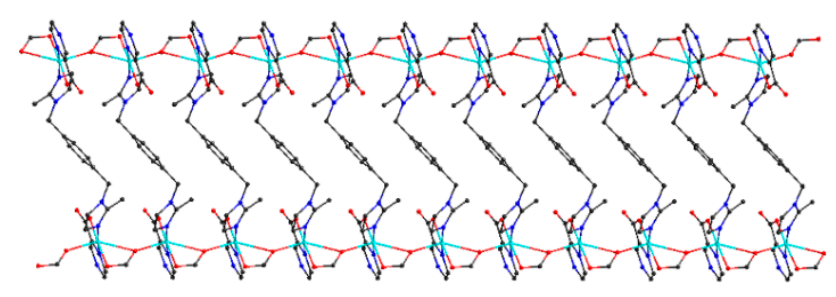

(c)

Figure 3. Cont. 


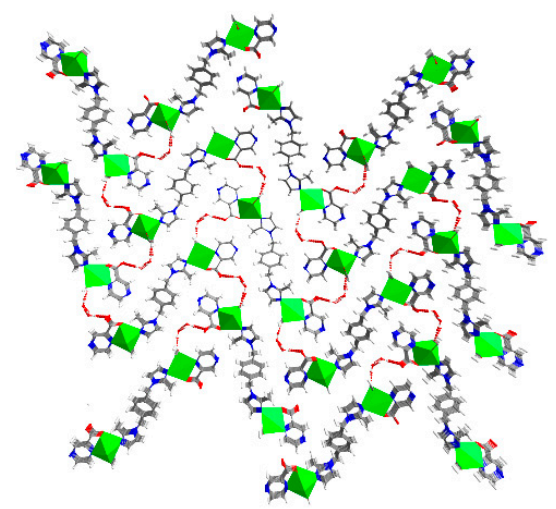

(d)

Figure 3. The structure of compound 3: (a) coordination environment of the $\mathrm{Cu}(\mathrm{II})$ ion (symmetry transformations used to generate equivalent atoms: ${ }^{1} 1+\mathrm{X},+\mathrm{Y},+\mathrm{Z} ;{ }^{2}-\mathrm{X},-\mathrm{Y},-\mathrm{Z} ;{ }^{3}-1+\mathrm{X},+\mathrm{Y}, \mathrm{Z}$ ); (b) the structure of infinitely-extended - $\mathrm{Cu}-\mathrm{O}-\mathrm{Cu}$ - chain; (c) 2D layer formed by hydrogen bonding;

(d) 3D framework relying on $\mathrm{O}-\mathrm{H} \cdots \mathrm{O}$ hydrogen bonds (turquiose, $\mathrm{Cu}$; red, O; blue, N; black, C).

\subsection{Structure Discussion}

As described above, three co-ligands with different coordination sites have marked effects on the structure. For 1, the structural extension is terminated due to a lack of coordination sites in the PhAA ligands, which makes 1 possess a 1D structure only. Although $\mathbf{2}$ and $\mathbf{3}$ have one of the same coordination sites (the functional groups circled by a dotted line in Figure 4), the type and position of another functional group results in different chain structures. As for $\mathbf{2}$, three coordination sites chelate copper ions like "crab claws", and as there is no coordination site present on the opposite side of the 2,6-PyDC ligand, the extension into a 2D structure is impossible. In the case of 3, the coordination sites circled by a dotted line chelate the copper ion and leave no suitable coordination conditions for the third functional group, resulting in $\mathbf{3}$ possessing a 1D ladder-shaped chain. In summary, a co-ligand with diverse coordination sites enriches structures with the same dimension.

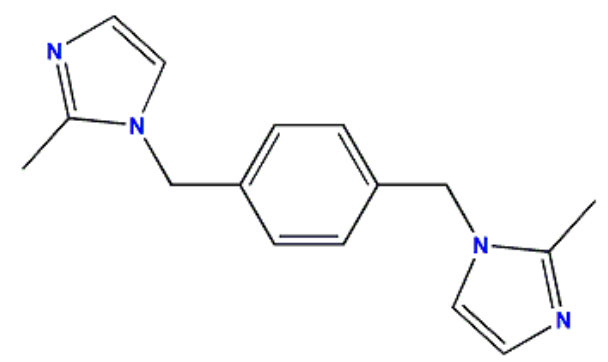

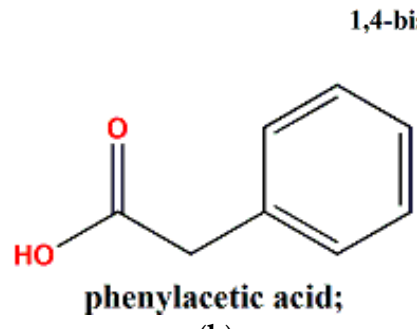

(b)

(a)

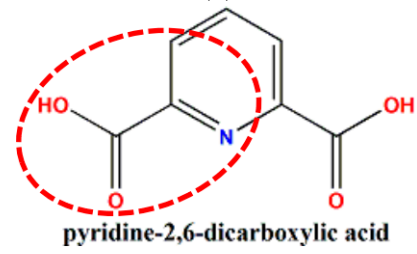

(c)

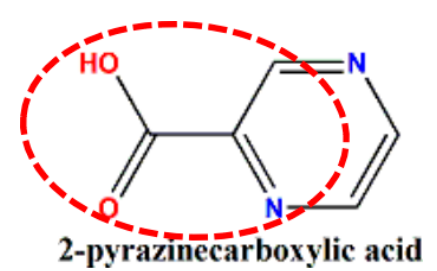

(d)

Figure 4. Construction of ligands for compounds 1-3: (a) the primary ligand of compounds 1-3, named 1,4-bmimb; (b) the co-ligand of $\mathbf{1}$, named PhAA; (c) the co-ligand of 2, named 2,6-PyDC; (d) the co-ligand of 3, named 2-PAC. Red dotted lines indicate corresponding functional groups. 


\subsection{XRD Analysis and Thermal Analysis}

The XRD patterns of the three compounds were measured at room temperature using a scanning range of $5^{\circ}$ to $40^{\circ}$. Figures S1-S3 show the PXRD patterns of the compounds 1-3 (red line) and the XRD pattern simulated from the single crystal structure (black line). The two lines are essentially in agreement, demonstrating that the synthesized compound is phase pure, i.e., does not contain an impurity phase. The difference in the reflection intensity between the simulated and experimental patterns is due to a certain degree of preferred orientation of the powder samples during data collection.

To examine the thermal stability of the three compounds, TGA was implemented in the temperature range of $25-800{ }^{\circ} \mathrm{C}$ under a steady $\mathrm{N}_{2}$ flow, the outcome of which is given in Figure 5. For 1, the decomposition starts at $158^{\circ} \mathrm{C}$. All uncoordinated water molecules (calculated for the asymmetric unit) were lost in the temperature range of $158^{\circ} \mathrm{C}$ to $200{ }^{\circ} \mathrm{C}$ (obsd $2.6 \%$, calcd $2.9 \%$ ). The compound then decomposed further at $420{ }^{\circ} \mathrm{C}$ with a weight loss of $49 \%$ (calcd $48.12 \%$ ), which was most probably due to the removal of PhAA ligands from the metal. At a temperature of $450{ }^{\circ} \mathrm{C}, \mathrm{ZnO}$ (obsd $13.12 \%$, calcd $13.14 \%$ ) was the final residue. The TGA curve of compound 2 shows the loss of 2,6-PyDC ligands in the temperature range of $200{ }^{\circ} \mathrm{C}$ to $240{ }^{\circ} \mathrm{C}$ (obsd 32\%, calcd $45.64 \%$ ). The observed weight loss is much less than the theoretical value, which is most likely due to the fact that the weight-loss process was not complete before the next step started. Finally, a residue of $\mathrm{CuO}$ (obsd $22.21 \%$, calcd $21.98 \%$ ) was left at $600{ }^{\circ} \mathrm{C}$. For 3, the first weight loss (obsd 6.9\%, calcd 9\%) was observed in the temperature range of $90{ }^{\circ} \mathrm{C}$ to $200^{\circ} \mathrm{C}$, due to the loss of two uncoordinated water molecules (calculated for the asymmetric unit). The observed weight loss of $20 \%$ in the temperature range of $200{ }^{\circ} \mathrm{C}$ to $240{ }^{\circ} \mathrm{C}$ (calcd $30.68 \%$ ) most likely corresponds with the loss of 2-PAC ligands. The reason this weight loss is much less than the theoretical value is similar to the reason given for 2 . At $670{ }^{\circ} \mathrm{C}$, the metal center was freed from all ligands, leaving behind the residue of $\mathrm{CuO}$ (obsd 19.54\%, calcd 19.86\%).

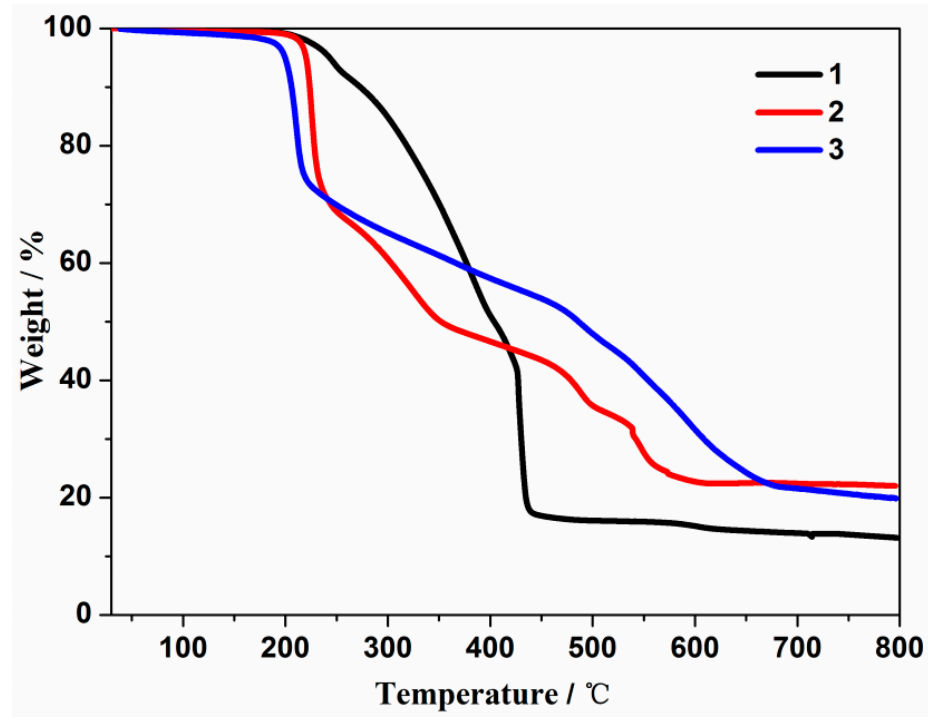

Figure 5. Curves of thermal gravimetric analysis (TGA) for compounds 1-3.

\subsection{Photoluminescent Properties and UV-Vis Spectra}

The luminescent properties of CPs with $\mathrm{d}^{10}$ metal centers have attracted intense interest because of their potential applications in chemical sensors, photochemistry, and electroluminescent displays [32-34]. Therefore, synthesizing a novel $\mathrm{Zn}(\mathrm{II})-\mathrm{CP}$ is a method for obtaining novel luminescent materials. The fluorescence properties of 1 and 1,4-bmimb ligand are shown in Figure $6\left(\lambda_{e x}=350 \mathrm{~nm}\right)$. When excited at $350 \mathrm{~nm}$, compound 1 and the 1,4-bmimb ligand showed strong fluorescence emission peaks at $442 \mathrm{~nm}$ and $453 \mathrm{~nm}$, respectively. The difference in peak position may be owing to the interaction of metal and ligand, or the interaction between molecules, such as $\pi \cdots \pi$ stacking. 


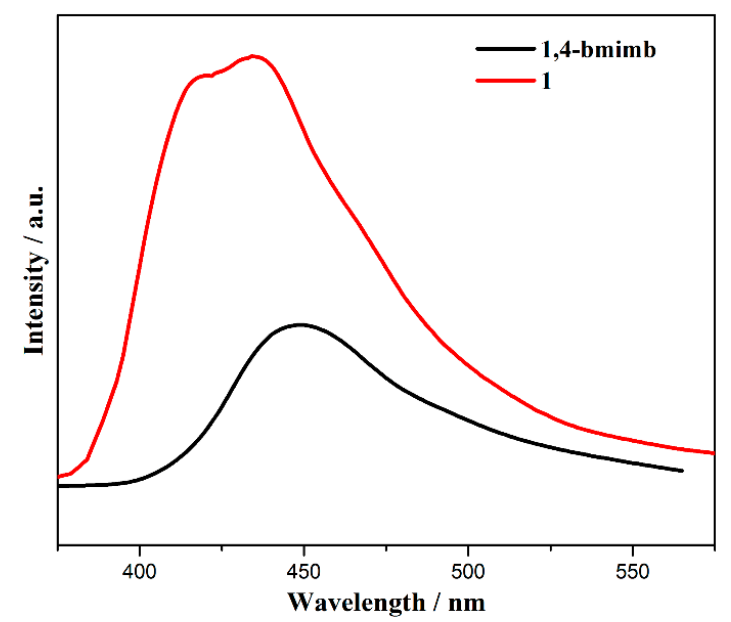

Figure 6. Fluorescence spectra of compound 1 and 1,4-bmimb ligand.

The UV-vis absorption spectra of $\mathbf{2}$ and $\mathbf{3}$ were given under the conditions of solid state and room temperature (Figure 7). In the UV region of the spectrum $(200-350 \mathrm{~nm})$, it is intraligand transitions that result in the absorption maxima from $200 \mathrm{~nm}$ to $270 \mathrm{~nm} .2$ and 3 also exhibit broad bands in the visible region with absorption maxima at $562 \mathrm{~nm}$ for 1 and $583 \mathrm{~nm}$ for 2, due to $\mathrm{d}-\mathrm{d}$ transitions (2Eg to $2 \mathrm{~T} 2 \mathrm{~g}$ transitions) of copper(II) compounds [35-37].

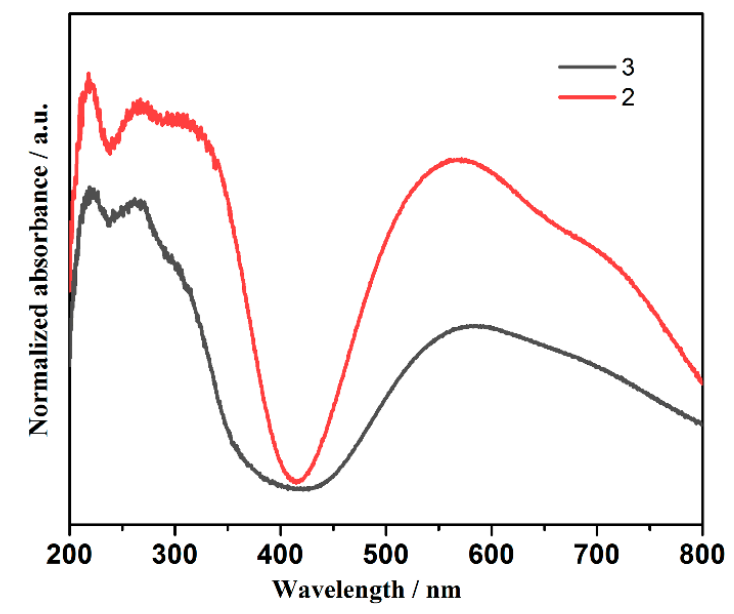

Figure 7. UV-vis absorption spectra of 2 and 3.

\section{Conclusions}

In conclusion, three novel CPs with diverse chain structures (Z-shaped chain, single chain and ladder-shaped chain) were successfully synthesized by the assembly of a 1,4-bmimb ligand, three other co-ligands, and zinc or copper ions. Each structure is assembled in a 3D supramolecular structure through intermolecular forces (hydrogen bonds and $\pi \cdots \pi$ interactions for $\mathbf{1}$ and $\mathbf{2}$, hydrogen bonds for 3). In addition, the thermal stability, XRD patterns, fluorescence spectra, and UV-vis absorption spectra of CPs were discussed in detail.

Supplementary Materials: The following are available online at http:/ /www.mdpi.com/2073-4352/8/7/288/s1, Table S1: Selected bond distances $(\AA)$ and angles $\left(^{\circ}\right)$ for 1, Table S2: Selected bond distances $(\AA)$ and angles $\left(^{\circ}\right)$ for 2, Table S3: Selected bond distances $(\AA)$ and angles $\left(^{\circ}\right)$ for 3, Table S4: Hydrogen bond distances $(\AA)$ and angles $\left(^{\circ}\right)$ for 1, Table S5: Hydrogen bond distances $(\AA)$ and angles $\left(^{\circ}\right)$ for 2, Table S6: Hydrogen bond distances $(\AA)$ and angles $\left(^{\circ}\right)$ for 3, Figure S1: The PXRD data of 1, Figure S2: The PXRD data of 2, Figure S3: The PXRD data of 3. 
Author Contributions: K.L. and Y.Z. conceived and designed the experiments; K.L. performed the experiments; L.D. and S.J. analyzed the data; L.W. supervised the work. All the authors have contributed to manuscript revision.

Funding: This work was supported by the National Natural Science Foundation of China (No. 21601103, 21701097, 21571112, 51572136 and 51772162), the Natural Science Foundation of Shandong Province, China (No. ZR2016BP04 and ZR2017BB080), the Scientific and Technical Development Project of Qingdao (No. 17-1-1-78-jch), and the Taishan Scholars Program.

Conflicts of Interest: The authors declare no conflict of interest.

\section{References}

1. Clearfield, A. Metal phosphonate chemistry. Prog. Inorg. Chem. 1998, 47, 371-510.

2. Eddaoudi, M.; Moler, D.B.; Li, H.; Chen, B.L.; Reineke, T.M.; O’Keeffe, M.; Yaghi, O.M. Modular chemistry: Secondary building units as a basis for the design of highly porous and robust metal-organic carboxylate frameworks. Acc. Chem. Res. 2001, 34, 319-330. [CrossRef] [PubMed]

3. Yaghi, O.M.; O'Keeffe, M.; Ockwig, M.; Chae, H.; Eddaoudi, M.; Kim, J. Reticular synthesis and the design of new materials. Nature 2003, 423, 705-714. [CrossRef] [PubMed]

4. Férey, G.; Mellot-Draznieks, C.; SerreSerre, C.; Millange, F.; Dutour, J.; Surblé, S.; Margiolaki, I. A chromium terephthalate-based solid with unusually large pore volumes and surface area. Science 2005, 309, $2040-2042$. [CrossRef] [PubMed]

5. Zhou, H.C.; Long, J.R.; Yaghi, O.M. Introduction to metal-organic frameworks. Chem. Rev. 2012, 112, $673-674$. [CrossRef] [PubMed]

6. Chen, L.; Ye, J.W.; Wang, H.P.; Pan, M.; Yin, S.Y.; Wei, Z.W.; Zhang, L.Y.; Wu, K.; Fan, Y.N.; Su, C.Y. Ultrafast water sensing and thermal imaging by a metal-organic framework with switchable luminescence. Nat. Commun. 2017, 8, 15985. [CrossRef] [PubMed]

7. Yang, Q.H.; Xu, Q.; Jiang, H.L. Metal-organic frameworks meet metal nanoparticles: Synergistic effect for enhanced catalysis. Chem. Soc. Rev. 2017, 46, 4774-4808. [CrossRef] [PubMed]

8. Tan, P.; Xie, X.Y.; Liu, X.Q.; Pan, T.; Gu, C.; Chen, P.F.; Zhou, J.Y.; Pan, Y.C.; Sun, L.B. Fabrication of magnetically responsive HKUST- $1 / \mathrm{Fe}_{3} \mathrm{O}_{4}$ composites by dry gel conversion for deep desulfurization and denitrogenation. J. Hazard. Mater. 2017, 321, 344-352. [CrossRef] [PubMed]

9. Wu, M.X.; Yang, Y.W. Metal-organic framework (MOF)-based drug/cargo delivery and cancer therapy. Adv. Mater. 2017, 29, 201606134. [CrossRef] [PubMed]

10. Ma, Y.L.; Du, L.; Wang, K.M.; Zhao, Q.H. Synthesis, crystal structure, luminescence and magnetism of three novel coordination polymers based on flexible multicarboxylate zwitterionic ligand. Crystals 2017, 7, 32. [CrossRef]

11. Liu, K.; Li, X.; Ma, D.X.; Han, Y.; Li, B.Y.; Shi, Z.; Li, Z.J.; Wang, L. A microporous yttrium metal-organic framework of an unusual nia topology for high adsorption selectivity of $\mathrm{C}_{2} \mathrm{H}_{2}$ and $\mathrm{CO}_{2}$ over $\mathrm{CH}_{4}$ at room temperature. Mater. Chem. Front. 2017, 1, 1982-1988. [CrossRef]

12. Song, B.H.; Ding, X.; Li, C.; An, G.F. Synthesis, crystal structures, and anti-liver cancer activity studies on three similar coordination polymers. Crystals 2018, 8, 207. [CrossRef]

13. Gu, J.Z.; Wen, M.; Liang, X.X.; Shi, Z.F.; Kirillova, M.V.; Kirillov, A.M. Multifunctional aromatic carboxylic acids as versatile building blocks for hydrothermal design of coordination polymers. Crystals 2018, 8, 83. [CrossRef]

14. Fan, L.M.; Fan, W.L.; Li, B.; Zhao, X.; Zhang, X.T. Coligand syntheses, crystal structures, luminescence and photocatalytic properties of five coordination polymers based on rigid tetracarboxylic acids and imidazole linkers. CrystEngComm 2015, 17, 9413-9422. [CrossRef]

15. Yang, Q.X.; Chen, X.Q.; Cui, J.H.; Hu, J.S.; Zhang, M.D.; Qin, L.; Wang, G.F.; Lu, Q.Y.; Zheng, H.G. Metal-organic frameworks based on flexible v-shaped polycarboxylate acids: Hydrogen bondings, non-interpenetrated and polycatenated. Cryst. Growth Des. 2012, 12, 4072-4082. [CrossRef]

16. Hu, J.S.; Huang, L.F.; Yao, X.Q.; Qin, L.; Li, Y.Z.; Guo, Z.J.; Zheng, H.G.; Xue, Z.L. Six new metal-organic frameworks based on polycarboxylate acids and v-shaped imidazole-based synthon: Syntheses, crystal structures, and properties. Inorg. Chem. 2011, 50, 2404-2414. [CrossRef] [PubMed] 
17. Han, M.L.; Duan, Y.P.; Li, D.S.; Wang, H.B.; Zhao, J.; Wang, Y.Y. Positional isomeric tunable two Co(II) 6-connected 3-D frameworks with pentanuclear to binuclear units: Structures, ion-exchange and magnetic properties. Dalton Trans. 2014, 43, 15450-15456. [CrossRef] [PubMed]

18. Liu, K.; Sun, Y.Y.; Deng, L.M.; Cao, F.; Han, J.S.; Wang, L. Cu(II) coordination polymers constructed by tetrafluoroterephthalic acid and varied imidazole-containing ligands: Syntheses, structures and properties. J. Solid State Chem. 2018, 258, 24-31. [CrossRef]

19. Liu, L.L.; Yu, C.X.; Li, Y.R.; Han, J.J.; Ma, F.J.; Ma, L.F. Positional isomeric effect on the structural variation of $\mathrm{Cd}(\mathrm{II})$ coordination polymers based on flexible linear/V-shaped bipyridyl benzene ligands. CrystEngComm 2015, 17, 653-664. [CrossRef]

20. Yu, M.H.; Zhang, P.; Feng, R.; Yao, Z.Q.; Yu, Y.C.; Hu, T.L.; Bu, X.H. Construction of a multi-cage-based MOF with a unique network for efficient $\mathrm{CO}_{2}$ capture. ACS Appl. Mater. Interfaces 2017, 9, 26177-26183. [CrossRef] [PubMed]

21. Wang, Y.; He, M.H.; Tian, Z.; Zhong, H.Y.; Zhu, L.S.; Zhang, Y.Y.; Zhang, X.P.; Chen, D.L.; He, Y.B. Rational construction of anssa-type of MOF through pre-organizing the ligand's conformation and its exceptional gas adsorption properties. Dalton Trans. 2018, 47, 2444-2452. [CrossRef] [PubMed]

22. Gu, T.Y.; Dai, M.; Young, D.J.; Ren, Z.G.; Lang, J.P. Luminescent Zn(II) coordination folymers for highly selective sensing of $\mathrm{Cr}(\mathrm{III})$ and $\mathrm{Cr}(\mathrm{VI})$ in water. Inorg. Chem. 2017, 56, 4668-4678. [CrossRef] [PubMed]

23. Cui, J.W.; Hou, S.X.; Hecke, K.V.; Cui, G.H. Rigid versus semi-rigid bis(imidazole) ligands in the assembly of two Co(II) coordination polymers: Structural variability, electrochemical properties and photocatalytic behavior. Dalton Trans. 2017, 46, 2892-2903. [CrossRef] [PubMed]

24. Hao, S.Y.; Hou, S.X.; Hecke, K.V.; Cui, G.H. Construction of noninterpenetrating and interpenetrating Co(II) networks with halogenated carboxylate modulated by auxiliary N-donor co-ligands: Structural diversity, electrochemical and photocatalytic properties. Dalton Trans. 2017, 46, 1951-1964. [CrossRef] [PubMed]

25. Sun, D.; Han, L.L.; Yuan, S.; Deng, Y.K.; Xu, M.Z.; Sun, D.F. Four new Cd(II) coordination polymers with mixed multidentate N-donors and biphenyl-based polycarboxylate ligands: Syntheses, structures, and photoluminescent properties. Cryst. Growth Des. 2013, 13, 377-385. [CrossRef]

26. Shi, L.L.; Zhang, Y.Q.; Han, S.S.; Yang, Z.; Zhu, L.M.; Li, B.L.; Li, H.Y. Syntheses, structures, properties of a series of coordination polymers with flexible bis(imidazole) and dicarboxylate ligands. Polyhedron 2017, 133, 82-91. [CrossRef]

27. Dobrzańska, L.; Lloyd, G.; Jacobs, T.; Rootman, I.; Oliver, C.; Bredenkamp, M.; Barbour, L. Construction of one- and two-dimensional coordination polymers using ditopic imidazole ligands. J. Mol. Struct. 2006, 796, 107-113. [CrossRef]

28. Xiao, Z.Y.; Yang, X.; Zhao, S.W.; Wang, D.B.; Yang, Y.; Wang, L. Metal-organic hybrid materials built with tetrachlorophthalate acid and different N-donor coligands: Structure diversity and photoluminescence. J. Solid State Chem. 2016, 234, 36-47. [CrossRef]

29. Blessing, R.H. A Program for the Siemens Area Detector Absorption Correction; University of Göttingen: Göttingen, Germany, 1997.

30. Sheldrick, G.M. SHELX-97, Program of Crystal Structure Solution; University of Göttingen: Göttingen, Germany, 1997.

31. Sheldrick, G.M. SHELX-97, Program of Crystal Structure Refinement; University of Göttingen: Göttingen, Germany, 1997.

32. Allendorf, M.D.; Bauer, C.A.; Bhakta, R.K.; Houk, R.J. Luminescent metal-organic frameworks. Chem. Soc. Rev. 2009, 38, 1330-1352. [CrossRef] [PubMed]

33. Braverman, M.A.; LaDuca, R.L. Luminescent two- and three-dimensional zinc coordination polymers containing isomers of phenylenediacetate and a kinked tethering organodiimine. Cryst. Growth Des. 2007, 7, 2343-2351. [CrossRef]

34. Lan, A.J.; Li, K.H.; Wu, H.H.; Olson, H.D.; Emge, T.J.; Ki, W.; Hong, M.C.; Li, J. A luminescent microporous metal-organic framework for the fast and reversible detection of high explosives. Angew. Chem. Int. Ed. 2009, 48, 2334-2338. [CrossRef] [PubMed]

35. Han, L.L.; Wang, S.N.; Jagličić, Z.; Zeng, S.Y.; Zheng, J.; Li, Z.H.; Chen, J.S.; Sun, D. Synthesis, structural versatility and magnetic properties of a series of copper(II) coordination polymers based on bipyrazole and various dicarboxylate ligands. CrystEngComm 2015, 17, 1405-1415. [CrossRef] 
36. Carranza, J.; Brennan, C.; Sletten, J.; Clemente-Juan, J.M.; Lloret, F.; Julve, M. Crystal structures and magnetic properties of 2,3,5,6-tetrakis(2-pyridyl)pyrazine (tppz)-containing copper(II) complexes. Inorg. Chem. 2003, 42, 8716-8727. [CrossRef] [PubMed]

37. Nath, J.K.; Mondal, A.; Powell, A.K.; Baruah, J.B. Structures, magnetic properties, and photoluminescence of dicarboxylate coordination polymers of $\mathrm{Mn}, \mathrm{Co}, \mathrm{Ni}, \mathrm{Cu}$ having N-(4-Pyridylmethyl)-1,8-naphthalimide. Cryst. Growth Des. 2014, 14, 4735-4748. [CrossRef]

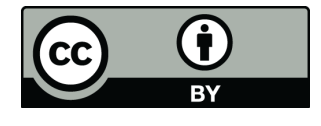

(C) 2018 by the authors. Licensee MDPI, Basel, Switzerland. This article is an open access article distributed under the terms and conditions of the Creative Commons Attribution (CC BY) license (http:/ / creativecommons.org/licenses/by/4.0/). 